\title{
A nested case-control study indicating heavy metal residues in meconium associate with maternal gestational diabetes mellitus risk
}

Siyuan Peng ${ }^{1+}$, Liangpo Liu $^{1+}$, Xueqin Zhang ${ }^{2 *}$, Joachim Heinrich ${ }^{3}$, Jie Zhang ${ }^{1}$, Karl-Werner Schramm ${ }^{4,5}$, Qingyu Huang ${ }^{1}$, Meiping Tian', Syed Ali Musstjab Akber Shah Eqani ${ }^{6}$ and Heqing Shen ${ }^{1 *}$

\begin{abstract}
Background: Environmental pollutant exposure may play certain roles in the pathogenesis and progression of diabetes mellitus including gestational diabetes mellitus (GDM). We hypothesize that heavy metal exposure may trigger GDM during pregnancy. The objective of this study was to investigate the possible associations between selected heavy metal exposure and GDM risk.

Methods: This investigation is a retrospective case-control study nested within a cohort of 1359 pregnant women. These participants were recruited in Xiamen Maternity and Child Care Hospital, China, during June to July, 2012. All their newborns' meconium samples were collected. By reviewing the antenatal care records, 166 GDM mothers were screened out from the 1359 participants; 137 of 166 GDM mothers offered their newborns' meconium samples for the metal analysis. Those 137 mothers were set as the case group. Similarly, 294 healthy mothers without any gestational complication were initially screened out from the rest 1193 non-GDM mothers. 190 of the 294 healthy mothers offered their newborns' meconium samples for the metal analysis. Those 190 mothers were set as the control group. Arsenic (As), mercury ( $\mathrm{Hg}$ ), lead ( $\mathrm{Pb})$, cadmium (Cd), and chromium ( $\mathrm{Cr}$ ) levels in these case-control meconium samples were measured by inductively coupled plasma mass spectrometry. The possible association between the metal levels and maternal GDM risk of studied subjects was assessed by binary logistic regression.
\end{abstract}

Results: GDM prevalence of $12.21 \%$ was observed in the investigated 1359 participants. The concentrations of As, $\mathrm{Hg}, \mathrm{Cr}$ and $\mathrm{Cd}$ in studied cases were significantly higher $(p<0.05)$ than those of controls. After adjustments for maternal age, pre-pregnant body mass index, gravidity, parity, hepatitis B virus infection, and newborn sex, As, Cd and $\mathrm{Cr}$ were found to be positively associated with GDM prevalence in dose-dependent manners. Among them, As was detected in all samples and its levels associated the maternal GDM with the adjusted odds ratios of 3.28 [95\% Cl $1.24,8.71], 3.35[95 \% \mathrm{Cl} 1.28,8.75]$ and $5.25[95 \% \mathrm{Cl} 1.99,13.86]$ for the $2^{\text {nd }}, 3^{\text {rd }}$ and $4^{\text {th }}$ quartiles, respectively.

Conclusions: The present work implies that exposure to some of the selected metals (noticeably As) may contribute to maternal GDM risk during pregnancy.

Keywords: Heavy metals, Meconium, Gestational diabetes mellitus, China

\footnotetext{
*Correspondence: wind459@126.com; hqshen@iue.ac.cn

${ }^{\dagger}$ Equal contributors

${ }^{2}$ Xiamen Maternity and Child Health Care Hospital, Xiamen 361003, PR China

${ }^{1}$ Key Laboratory of Urban Environment and Health, Institute of Urban

Environment, Chinese Academy of Sciences, Xiamen 361021, PR China

Full list of author information is available at the end of the article
}

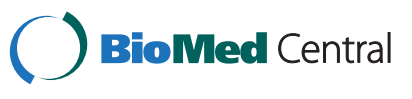

(c) 2015 Peng et al.; licensee BioMed Central. This is an Open Access article distributed under the terms of the Creative Commons Attribution License (http://creativecommons.org/licenses/by/4.0), which permits unrestricted use, distribution, and reproduction in any medium, provided the original work is properly credited. The Creative Commons Public Domain Dedication waiver (http://creativecommons.org/publicdomain/zero/1.0/) applies to the data made available in this article, unless otherwise stated. 


\section{Background}

It has been reported that a dramatic rise of worldwide diabetic people is expected to occur up to 366 million in forthcoming 30 years and preventative actions are needed to take to tone down this global issue [1]. In China, approximately 40 million people are suffering from type 2 diabetes (T2DM) [2]. Gestational diabetes mellitus (GDM) is defined as the symptom of the impaired glucose tolerance (IGT) with the onset during pregnancy [3] and some reports also documented its high prevalence rate in China [2]. GDM is an endocrine and metabolic disease and occurs when a woman's pancreatic function is not sufficient to overcome the diabetogenic environment of pregnancy [4], which has been considered as a 'pre-diabetic' state and its pathophysiology is clearly related to T2DM [5]. It has become one of the predictors of T2DM in the later life of the mothers and their offspring by playing a key role in the rapidly increasing diabetes incidence via the unknown reason of 'diabetes begetting diabetes' [2]. Several definite traditional risk factors associated with the development of GDM includes maternal age, obesity, history of macrosomia, and strong family history of diabetes [3,4].

Besides the changes in human lifestyle and behavior (e.g. poor diet, lack of exercise) and the genetic predisposition [6], recently environmental pollutants have been suggested to pose additional risk to diabetes development [7-9]. Heavy metals have been described to exhibit some diabetogenic properties $[7,8]$. Exposure to mercury $(\mathrm{Hg})$, lead $(\mathrm{Pb})$, cadmium $(\mathrm{Cd})$ and the metalloid arsenic (As) have been linked to the increasing incidence of T2DM by several reports $[10,11]$. The fact can be further explained by considering the example from Arseniosisepidemic areas of Taiwan and Bangladesh [12], where the authors clearly observed the striking association between arsenic burdens and incidence of diabetes mellitus. Furthermore, exposure to these heavy metals during pregnancy may impact the sensitive hormonal activities and ultimately increase the risk of GDM by favoring the shift towards diabetes (i.e., diabetogenic environment of pregnancy) [2]. Hence, the scenario encouraged metabolic disruption during pregnancy [13], and supports the hypothesis that maternal exposure to heavy metals during pregnancy may contribute to higher GDM risk.

The need to check the prenatal exposure to pollutants has led the scientists to various bio-monitoring strategies involving the use of newborn meconium. Meconium, being the first stools of the newborn, offers several advantages to assess the prenatal exposure of wide range environmental contaminants [14]. The potential of using meconium is primarily due to its formation accompanied with the fetus growing as early as the $12^{\text {th }}$ week of gestation and its accumulation till the child birth, so that long-term exposure (i.e., over the last two trimesters of pregnancy) of different environmental pollutants including heavy metals can be signaled by associated maternal response [14-16]. In contrast to some traditional matrices such as urine, cord blood and amniotic fluid, which have several limitation e.g., ethical issues, difficult to collect and reflect only transient and/or recent exposure of pollutants, meconium also offers advantages including ease in sampling and non-invasive analysis [17]. In addition, it acts as a promising mutual sample to indicate both the prenatal and maternal exposure, and it also contained relatively more pollutant burden than other tissues, hence easier to detect and quantify. On the other hand, some studies had also addressed association between pollutant exposure and neonatal health outcomes by meconium analysis $[14,17]$, but few studies addressed the maternal health condition like GDM.

However in the last decade, strong disagreements have arisen between supporters and opponents of the role of environmental chemicals in the developing diabetes observed in several regions of the world $[7,8,12]$. The link between GDM prevalence and environmental chemical exposure is also hampered by the complexity of the chemical mixtures present into the environment, both in terms of the numbers of compounds and the mechanisms by which they can affect subjects. Furthermore, most of epidemiological studies have been conducted from high contaminated area in order to study the effects of toxic metals [12], whereas trace metal toxicity due to different exposure routes and environmental conditions are ambiguous and need to be confirmed. Hence keeping in view the mentioned hypothesis of GDM risk and its linkages with heavy metals burdens, we designed a retrospective case-control study nested within a cohort of 1359 participants to investigate the associations between gestational exposure to some heavy metals and GDM risk. Paired mother-newborn clinical records of recruited subjects were collected and heavy metals of prime environmental concern and potential diabetes risk $[10,18]$, i.e. chromium $(\mathrm{Cr}), \mathrm{Cd}, \mathrm{Hg}, \mathrm{Pb}$ and metalloid $\mathrm{As}$ were assessed in their meconium samples based on case-control approach, to study the possible association of heavy metals and GDM risk.

\section{Methods}

\section{Participant recruitment and GDM screening}

The basic work flow of participant recruitment and case-control selection has shown as Figure 1. The participants of approximate 1500 pregnant women were approached, when they were admitted in hospital and expected to delivery. They were enrolled by gynecologists 1-3 days before their delivery in Xiamen Maternity and Child Care Hospital (Xiamen, China), from June to July, 2012. The subjects were informed about the objective of the study and solicited to participate after 


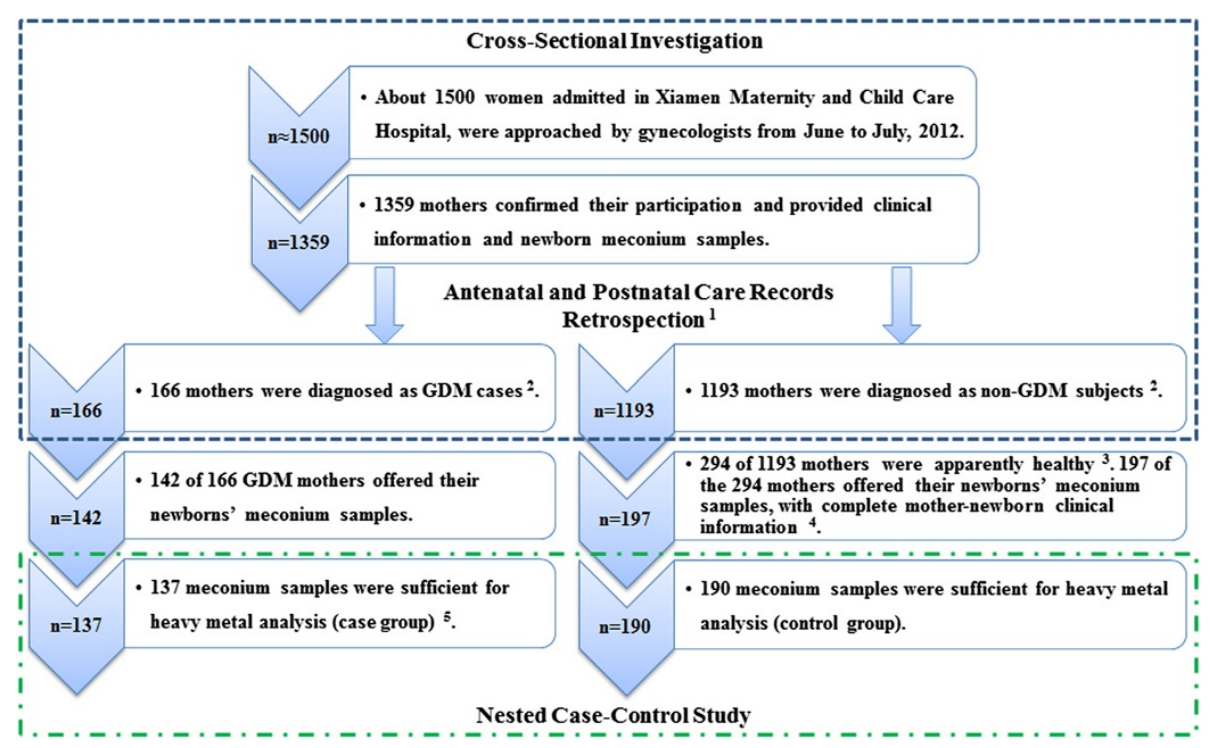

Figure 1 Flowchart of the participant recruitment and case-control selection. ${ }^{1}$ Clinical information of the participants was acquired from antenatal and postnatal care record retrospection, including all maternal gestational complications and neonatal disorders (Additional file 1: Table S2). ${ }^{2} \mathrm{GDM}$ and non-GDM mothers were diagnosed during the 24 to $28^{\text {th }}$ gestational week. GDM cases were selected out through antenatal care record retrospection. ${ }^{3}$ Apparently healthy mothers without any recorded gestational complication were selected out from the 1193 non-GDM mothers (i.e., any complication potentially related to GDM was excluded), so the final controls had no GDM risk. ${ }^{4}$ Complete mother-newborn clinical information includes: A mother's basic clinical characteristics (i.e. age, pre-pregnant BMl, gestational age, gravidity, parity, mode of delivery), gestational complications, history of drinking and smoking during pregnancy, history of macrosomic infant delivery, history of diabetes or obesity of herself and her spouse, and her newborn's sex, birth weight and neonatal disorders. ${ }^{5}$ Most clinical information of those 137 mothers was available, except that 36 of 137 cases missed the maternal age or pre-pregnant BMI information. Metals exposure data of all 137 samples were included in the final statistical analysis.

providing written consents by the gynecologists. The right to refuse participation and the fact that this refusal would not have any consequence on the relation with their physician, as well as the obligation of providing clinical information and authentic self-reported historical information during pregnancy, was explicitly mentioned. A total of 1359 mothers (mean age 26.90 years, mean pre-pregnant body mass index (BMI) $21.05 \mathrm{~kg} / \mathrm{m}^{2}$ ) confirmed their participation by signing the consent forms and they all received complete antenatal and postnatal care in hospital. Clinical information of the mother-newborns was acquired from antenatal and postnatal care records. In addition, history of smoking, drinking during pregnancy, previous disease history of all the participants and their spouses were interviewed and recorded by the gynecologists during antenatal care.

Among the 1359 confirmed participants, GDM cases were selected out through retrospection of the maternal antenatal care records. GDM screening is a universal medical program in China which is nationally required and performed for every mother who receives antenatal care in hospital, by performing the glucose tests during the 24 to $28^{\text {th }}$ gestational week. All participants accepted the test and GDM cases among them were diagnosed and recorded. Briefly, the GDM screening tests consisted of a $50 \mathrm{~g}$ 1-hour glucose test (glucose challenge test) and a further oral glucose tolerance test (OGTT) based on the World Health Organization (WHO) criteria [19]. Venous blood was taken $60 \mathrm{~min}$ after the ingestion of $200 \mathrm{~mL}$ of $25 \%$ glucose solution. Mothers, with a record of $\geq 7.8 \mathrm{mmol} / \mathrm{L}$ glucose at the initial screening were invited to undergo a $75 \mathrm{~g}$ 2-hour OGTT. Diabetes is defined as fasting serum glucose $\geq 7.0 \mathrm{mmol} / \mathrm{L}$ and/or 2-hour serum glucose $\geq 11.1 \mathrm{mmol} / \mathrm{L}$, and impaired glucose tolerance (IGT) is defined as 2-hour serum glucose $\geq 7.8$ and $<11.1 \mathrm{mmol} / \mathrm{L}$ and fasting serum glucose $<7.0 \mathrm{mmol} / \mathrm{L}$. Women who had confirmed either diabetes and/or IGT are regarded as the GDM cases. One diagnosed pre-gestational diabetes case (self-report) was excluded. A total of 166 subjects were diagnosed and recorded as GDM cases in the recruited cohort of 1359 participants, with GDM prevalence of $12.21 \%$.

\section{Sample collection and case-control selection}

Newborn meconium samples from the recruited cohort were collected by using the diapers during the first two postnatal days. The diapers were sealed in the acidwashed containers and stored at $-20^{\circ} \mathrm{C}$ till the further treatment. 
The selection of the cases was as follows: (1) During the 24 to $28^{\text {th }}$ gestational week, mothers were diagnosed as GDM cases (166 subjects); (2) Newborn meconium samples were successfully collected (142 subjects); (3) Samples were sufficient for heavy metal residues analysis (137 subjects, set as the case group). The selection of the controls was as follows: (1) During the 24 to $28^{\text {th }}$ gestational week, mothers were diagnosed as non-GDM cases (1193 subjects); (2) Mothers were apparently healthy, without any recorded gestational complication (Additional file 1: Table S2) (294 subjects); (3) Complete mother-newborn information was available and newborn meconium samples were successfully collected (197 subjects); (4) Samples were sufficient for heavy metal residues analysis (190 subjects, set as the control group). For both groups, mothers had (1) no smoking and drinking history during pregnancy; (2) no previous delivery of the macrosomic infant (birth weight $>4 \mathrm{~kg}$ ); (3) no self-reported diabetes or obesity history of themselves and their spouses. The basic workflow of this study is shown in Figure 1.

\section{Sample preparation and heavy metal analysis}

Meconium samples were dried by a freeze dryer (Boyikang Corporation, Beijing, China) and ground into powder. Dry meconium $(100 \mathrm{mg})$ was digested with a mixture of $1 \mathrm{~mL}$ $65 \%(\mathrm{v} / \mathrm{v}) \mathrm{HNO}_{3}$ and $1 \mathrm{~mL} 30 \%(\mathrm{v} / \mathrm{v}) \mathrm{H}_{2} \mathrm{O}_{2}$ in a water bath at $100^{\circ} \mathrm{C}$ for at least $5 \mathrm{~h}$, and adjusted to a final volume of $5 \mathrm{~mL}$ with ultra-pure water. Spiked samples were also prepared in the same procedure to measure recoveries. More details about the sample preparation were described in Additional file 1: Text S1.

Heavy metal residues in meconium were determined by using Agilent $7500 \mathrm{cx}$ inductively coupled plasma mass spectrometry (ICP-MS) (Agilent Technologies, Santa Clara, CA, USA). The calibration curves, linear ranges (LR), relative coefficients $\left(\mathrm{r}^{2}\right)$ of calibration curves, the limit of detections (LOD), and the recoveries were listed in Additional file 1: Table S1. The strict quality control and quality assurance (QC/QA) in the analytical procedure were also followed and described in Additional file 1: Text S2.

\section{Statistical analysis \\ Data imputation}

Undetected values of metals were imputed using the default value of $1 / 2$ limit of detection (LOD) when the detection frequency $\geq 90 \%$; otherwise, missing values were excluded to avoid any statistical bias [20,21]. Therefore, missing values of $\mathrm{Pb}$ were imputed by $1 / 2$ LOD while missing values of $\mathrm{Cr}$ and $\mathrm{Cd}$ were excluded from statistical analysis.

\section{Difference comparison}

Independent sample $t$-test and non-parametric MannWhitney $U$ test were applied to compare the differences between two groups, for normally distributed and nonnormally distributed continuous variables, respectively. Fisher's exact test was applied to compare difference for categorical variables with total observed frequency $\leq 40$, otherwise, Pearson Chi-square test was applied.

\section{Dose-response relationship}

The associations between heavy metal levels and GDM prevalence were examined using binary logistic regressions. The heavy metal levels were transformed into categorical variables based on quartile cutoffs of the controls. Values of $\mathrm{Cr}$ and $\mathrm{Cd}$ were also transformed into three categorical variables based on cutoff-points at $50 \%$ and $75 \%$ values of the controls. Trend analysis was evaluated by linear by linear association Chi-square $[22,23]$. Adjustments were made for six suspected prenatal GDM risk factors (i.e., maternal age, pre-pregnant BMI, gravidity, parity, hepatitis B virus (HBV) infection, and newborn sex). Adjustments were made for maternal age, pre-pregnant BMI, gravidity and parity because those factors have been associated with GDM [3-5]. Adjustments were also made for newborn sex, because hormonal activities during pregnancy may be affected by fetal sexual differentiation [24], which may also contribute to GDM risk. All the recorded gestational complications were listed and compared in this recruited cohort (Additional file 1: Table S2). HBV infection, umbilical cord disorders, and precipitate labor were found to be significantly different between GDM and non-GDM group. However, only HBV infection is a prenatal factor which has been associated with GDM $[25,26]$ while umbilical cord disorders and precipitate labor are likely to be the GDM induced pregnancy outcomes. Therefore, adjustment was made for HBV infection.

The statistical analysis was performed with SPSS version 18.0 (SPSS Inc., Chicago, IL). P value of less than 0.05 was considered to be significantly statistical difference.

\section{Results}

\section{Clinical characteristics of 1359 participants}

The total 1359 confirmed participants included 166 GDM and 1193 non-GDM mothers. The general clinical characteristics were listed and compared in Additional file 1: Table S3. Among them, maternal age and prepregnant BMI were significantly different $(p<0.05)$ between GDM and non-GDM mothers, with lower gestational age and higher incidence of C-section (Caesarean section) (27.71\%) in GDM group. The scenario suggested potential association between higher maternal age, BMI and GDM risk, which is in agreement with previous investigations [3-5]. Furthermore, the occurrence of maternal HBV infection (i.e., HBsAg positive, measured during gestation from 25 to $28^{\text {th }}$ week in antenatal care for each 
mother), and some pregnancy outcomes (i.e. umbilical cord disorders and precipitate labor) were significantly different between the GDM and non-GDM mothers (Details were shown in Additional file 1: Table S2), suggesting that HBV infection may be a GDM risk factor in this cohort, and GDM may has adverse effects on pregnancy outcomes.

\section{Clinical characteristics of subjects in nested case-control group}

137 GDM cases from the 166 GDM mothers and 190 controls from the 1193 non-GDM mothers were selected for the heavy metal exposure analysis and GDM risk assessment. The maternal and newborn clinical characteristics were summarized in Table 1. All factors except newborn birth weight and sex showed significant

\section{Table 1 Clinical characteristics of the mothers and} newborns in nested case-control group ${ }^{a}$

\begin{tabular}{|c|c|c|c|}
\hline & Case $(n=137)$ & Control $(n=190)$ & $p^{b}$ \\
\hline Newborn birth weight (kg) & $3.29 \pm 0.38$ & $3.23 \pm 0.30$ & 0.080 \\
\hline Maternal age (year) ${ }^{c}$ & $27.85 \pm 3.87$ & $26.34 \pm 2.64$ & $<0.001^{* *}$ \\
\hline $\begin{array}{l}\text { Maternal pre-pregnant } \\
\text { BMI }\left(\mathrm{kg} / \mathrm{m}^{2}\right)^{\mathrm{d}}\end{array}$ & $21.89 \pm 2.92$ & $20.59 \pm 2.27$ & $<0.001^{* *}$ \\
\hline Gestational age (week) & $39.18 \pm 0.80$ & $39.55 \pm 0.92$ & $<0.001^{* *}$ \\
\hline \multicolumn{4}{|l|}{ Newborn sex } \\
\hline Male & $72(52.55 \%)$ & $93(48.95 \%)$ & 0.520 \\
\hline Female & 65 (47.45\%) & 97 (51.05\%) & \\
\hline \multicolumn{4}{|l|}{ Maternal gravidity } \\
\hline 1 & $82(59.85 \%)$ & $134(70.53 \%)$ & $0.034^{*}$ \\
\hline 2 & $29(21.17 \%)$ & $38(20.00 \%)$ & \\
\hline$\geq 3$ & $26(18.98 \%)$ & $18(9.47 \%)$ & \\
\hline \multicolumn{4}{|l|}{ Maternal parity } \\
\hline 1 & $114(83.21 \%)$ & $174(91.58 \%)$ & $0.049^{*}$ \\
\hline 2 & $22(16.06 \%)$ & $16(8.42 \%)$ & \\
\hline$\geq 3$ & $1(0.73 \%)$ & $0(0.00 \%)$ & \\
\hline \multicolumn{4}{|l|}{ Mode of delivery } \\
\hline Eutocia & $92(67.15 \%)$ & $176(92.63 \%)$ & $<0.001^{* *}$ \\
\hline C-section & $39(28.47 \%)$ & $13(6.84 \%)$ & \\
\hline Aid delivery & $6(4.38 \%)$ & $1(0.53 \%)$ & \\
\hline \multicolumn{4}{|l|}{ Maternal HBsAg } \\
\hline Positive & $24(17.65 \%)$ & $0(0.00 \%)$ & $<0.001^{* *}$ \\
\hline Negative & $112(82.35 \%)$ & 190 (100.00\%) & \\
\hline
\end{tabular}

${ }^{\mathrm{a} V a l u e s}$ of newborn birth weight, maternal age, pre-pregnant BMl and gestational age are expressed as mean $\pm \mathrm{SD}$.

${ }^{b} \mathrm{p}$ values of maternal age, pre-pregnant $\mathrm{BMI}$ and gestational age were obtained by non-parametric Mann-Whitney $U$ test, $p$ values of newborn birth weight was obtained by independent sample $t$-test, while $p$ values of maternal gravidity and parity, mode of delivery were obtained by Pearson Chi-square test, $p$ values of HBsAg was obtained by Fisher's exact test. ${ }^{*}$ indicates $p<0.05,{ }^{* *}$ indicates $p<0.01$. 'Values from 101 subjects in case group were available.

${ }^{d}$ Values from 103 subjects in case group were available. difference between the cases and controls (Table 1). Given that fetal sexual differentiation and development may affect maternal hormonal activities during pregnancy [24], the maternal and newborn clinical characteristics between the selected cases and controls were also compared separately on newborn sex (see Additional file 1: Table S4). For the mothers who delivered boys, all maternal factors were significantly different between the case and control groups. While for mothers who delivered girls, the maternal age, gravidity, parity did not showed difference between the case and control groups. Therefore, fetal sex might play a certain role in maternal status during gestation.

\section{Meconium heavy metal profiling in nested case-control group}

The detection frequencies of As and $\mathrm{Hg}$ were all 100\% in both groups. For $\mathrm{Pb}, \mathrm{Cd}$ and $\mathrm{Cr}$, the detection frequencies were $89.78 \%, 100 \%$ and $55.47 \%$ in case group, respectively; and $97.37 \%, 45.79 \%$ and $70 \%$ in control group, respectively. The levels of As (median $=49.75$ and $37.78 \mathrm{ng} / \mathrm{g}$ in cases and controls, respectively), $\mathrm{Hg}$ (median $=34.40$ and $28.66 \mathrm{ng} / \mathrm{g}$ in cases and controls, respectively), $\mathrm{Cr}$ (median $=56.43$ and $25.96 \mathrm{ng} / \mathrm{g}$ in cases and controls, respectively) and $\mathrm{Cd}$ (median $=9.41$ and $4.10 \mathrm{ng} / \mathrm{g}$ in cases and controls, respectively) in the meconium samples of the cases were significantly higher than those in the controls $(p<0.05)$. In contrast, $\mathrm{Pb}$ levels (median $=146.90$ and $135.68 \mathrm{ng} / \mathrm{g}$ in cases and controls, respectively) were found at very high levels in the study subjects but without significant difference $(p>0.05)$. More details were described in Table 2 . Therefore, $\mathrm{As}, \mathrm{Hg}, \mathrm{Cr}$ and $\mathrm{Cd}$ were suspected to induce maternal GDM risk.

\section{GDM risk assessment of the selected metals in nested case-control group}

To address the potential relationships between maternal exposure to the selected metals and GDM risk, adjustments were made for six factors (i.e. maternal age, prepregnant $\mathrm{BMI}$, gravidity, parity, $\mathrm{HBV}$ infection, and newborn sex). The adjusted results were shown in Table 3 and Additional file 1: Table S5, and the unadjusted results were presented in Additional file 1: Tables S6 and S7. Positive dose-dependent trends were observed for As, $\mathrm{Cd}$ and $\mathrm{Cr}$. In comparison of the $1^{\text {st }}$ quartile, As levels associated the maternal GDM with the adjusted odds ratios (AORs) 3.28 [95\% CI 1.24, 8.71], 3.35 [95\% CI 1.28, 8.75] and 5.25 [95\% CI 1.99, 13.86] for the $2^{\text {nd }}, 3^{\text {rd }}$ and $4^{\text {th }}$ quartiles, respectively; $\mathrm{Cd}$ levels associated the GDM with AORs 16.87 [95\% CI $4.19,67.86]$ and 11.95 [95\% CI 2.97, 48.04] for the $3^{\text {rd }}$ and $4^{\text {th }}$ quartiles, respectively. Cr level was significantly associated with GDM risk only for the $4^{\text {th }}$ quartile 
Table 2 Profiling of heavy metals in meconium (ng/g dry weight) of nested case-control group ${ }^{a}$

\begin{tabular}{|c|c|c|c|c|}
\hline Metal & & Case $(n=137)$ & Control $(n=190)$ & $p^{b}$ \\
\hline \multirow[t]{5}{*}{ As } & $\begin{array}{l}\text { Detected Number } \\
\text { (ratio) }\end{array}$ & 137 (100.00\%) & $190(100.00 \%)$ & $<0.001^{* *}$ \\
\hline & Median & 49.75 & 37.78 & \\
\hline & IQR & $32.51-82.42$ & $23.98-64.56$ & \\
\hline & Mean & 60.81 & 45.15 & \\
\hline & SD & 37.19 & 28.71 & \\
\hline \multirow[t]{5}{*}{$\mathrm{Hg}$} & $\begin{array}{l}\text { Detected Number } \\
\text { (ratio) }\end{array}$ & 137 (100.00\%) & $190(100.00 \%)$ & $0.001^{* *}$ \\
\hline & Median & 34.40 & 28.66 & \\
\hline & IQR & $25.62-47.36$ & $20.42-40.30$ & \\
\hline & Mean & 41.27 & 37.56 & \\
\hline & $\mathrm{SD}$ & 27.09 & 54.34 & \\
\hline \multirow[t]{5}{*}{$\mathrm{Pb}$} & $\begin{array}{l}\text { Detected Number } \\
\text { (ratio) }\end{array}$ & $123(89.78 \%)$ & 185 (97.37\%) & 0.534 \\
\hline & Median & 146.90 & 135.68 & \\
\hline & IQR & 49.96-389.10 & $75.61-216.54$ & \\
\hline & Mean & 283.96 & 195.55 & \\
\hline & SD & 393.04 & 216.32 & \\
\hline \multirow[t]{5}{*}{$\mathrm{Cr}$} & $\begin{array}{l}\text { Detected Number } \\
\text { (ratio) }\end{array}$ & 76 (55.47\%) & $133(70.00 \%)$ & $<0.001^{* *}$ \\
\hline & Median & 56.43 & 25.96 & \\
\hline & IQR & 18.19-116.45 & $10.13-53.33$ & \\
\hline & Mean & 91.75 & 47.99 & \\
\hline & SD & 105.69 & 66.54 & \\
\hline \multirow[t]{5}{*}{$\mathrm{Cd}$} & $\begin{array}{l}\text { Detected Number } \\
\text { (ratio) }\end{array}$ & 137 (100.00\%) & $87(45.79 \%)$ & $<0.001^{* *}$ \\
\hline & Median & 9.41 & 4.10 & \\
\hline & IQR & $5.59-15.23$ & $1.47-11.32$ & \\
\hline & Mean & 18.55 & 10.00 & \\
\hline & SD & 35.44 & 17.48 & \\
\hline
\end{tabular}

${ }^{a}$ Missing values of $\mathrm{Pb}$ were imputed by $1 / 2$ LOD while missing values of $\mathrm{Cr}$ and $\mathrm{Cd}$ were excluded from statistics.

IQR: Inter-quartile range, 25\%-75\%.

${ }_{\mathrm{b}}^{\mathrm{p}}$ value was obtained by non-parametric Mann-Whitney $U$ test.

${ }^{* *}$ indicates $\mathrm{p}<0.01$.

samples with AOR 4.48 [95\% CI, 1.40, 14.31]. The observed AORs with high $\mathrm{CI}$ ranges for $\mathrm{Cd}$ and $\mathrm{Cr}$ may be attributed to many of the missed data for the control subjects at the low level. When $\mathrm{Cd}$ and $\mathrm{Cr}$ values were transformed to three levels with values below median as reference cutoff (Additional file 1: Table S5), Cd levels were associated the GDM with AORs 8.26 [95\% CI 3.39, 20.12] and 5.82 [95\% CI 2.39, 14.16] for the $2^{\text {nd }}$ and $3^{\text {rd }}$ cutoff, respectively. Cr level was significantly associated with GDM risk at only $3^{\text {rd }}$ cutoff with AORs 3.27 [95\% CI 1.35, 7.93]. The significance of association for $\mathrm{Cd}$ and $\mathrm{Cr}$ kept at high levels. The trend for As, $\mathrm{Cd}$ and $\mathrm{Cr}$ was all significant under all circumstances.
The dose-dependent relationship for $\mathrm{Hg}$ was noticeable before adjustment but not noticeable after adjustment. However, the trend for $\mathrm{Hg}$ kept significant. The significant AORs of 0.37 [95\% CI $0.16,0.86$ ] and 0.16 [95\% CI 0.06, 0.44] were observed for $\mathrm{Pb}$ in the $2^{\text {nd }}$ and $3^{\text {rd }}$ quartiles, respectively. Besides, the trend of linear association for $\mathrm{Pb}$ with GDM risk was not noticeable. These ambiguous trends may generally reflect inconclusive correlation between $\mathrm{Pb}, \mathrm{Hg}$ and GDM risk.

\section{Discussion}

GDM incidence and some maternal risk factors

GDM incidences ranged from 1 to $14 \%$ worldwide [27]. In mainland of China, few studies reported the GDM incidence in different cities and explained possible risk factors. A large prospective study of 16286 pregnant women from 18 cities in China reported the GDM incidence was $4.3 \%$ [28], which is quite lower than that reported in current study (12\%). This may be attributed towards distinct GDM risk factors at spatial scale. Therefore, the preliminary result from this nested casecontrol study suggested that the total 1359 participants might suffer from relatively higher GDM risk. In general, maternal age, pre-pregnant BMI, gravidity and parity, are the common GDM risk factors for Asian women [3-5,29], which are also observed in present study. The other definite risk factor is HBV infection, which had also been observed to increase the GDM risk in previous reports $[25,26]$. Moreover, our results also imply that the 'diabetogenic environment of pregnancy' may be further aggravated due to exposure to some heavy metals (i.e. As, $\mathrm{Cd}$ and $\mathrm{Cr}$ ), in which these metals may act as obesogens to induce GDM risk [7-9,30].

\section{The gestational exposure to selected heavy metals}

Heavy metals have been known to be able to transfer via placenta and penetrate into developing fetus by bioaccumulation [31-33]. Meconium is the fetal repository which traps the trans-placental xenobiotic residues during pregnancy and reflects exposure history. This matrix has been previously used to detect fetal exposure to a number of xenobiotic agents including drugs, alcohol metabolites, nicotine metabolites [14] and heavy metals (Table 4). However, only few studies addressed the maternal exposure by meconium $[15,17]$. In this study, the profiling of detected heavy metal residues in meconium suggested that the participants might commonly expose to these metals (Table 2). Compared to other reports, the extent of exposure may be area specific (Table 4), e.g., $\mathrm{Pb}, \mathrm{Hg}$ and $\mathrm{Cd}$ exposure in inhabitants from heavily contaminated regions and/or industrialized metropolis [34-36] is noticeably higher than those from remote and/or rural areas $[14,37,38]$. Selected metals detected in our studied subjects may have similar sources, 
Table 3 Associations of heavy metals with adjusted odds ratio (AOR) of GDM in nested case-control group ${ }^{\text {a }}$

\begin{tabular}{|c|c|c|c|c|c|c|}
\hline Metal & Control and case & 1st quartile (Reference) & 2nd quartile & 3rd quartile & 4th quartile & $p$ trend $^{b}$ \\
\hline \multirow[t]{4}{*}{ As } & Control (\%) & $47(24.74 \%)$ & $48(25.26 \%)$ & $48(25.26 \%)$ & $47(24.74 \%)$ & \\
\hline & Case (\%) & $11(8.03 \%)$ & $32(23.36 \%)$ & $44(32.12 \%)$ & $50(36.50 \%)$ & \\
\hline & $\operatorname{AOR}(95 \% \mathrm{Cl})^{c}$ & 1 & $3.28(1.24-8.71)$ & $3.35(1.28-8.75)$ & $5.25(1.99-13.86)$ & \\
\hline & $p$ value ${ }^{d}$ & & $0.017^{*}$ & $0.014^{*}$ & $0.001^{* *}$ & $<0.001^{* *}$ \\
\hline \multirow[t]{4}{*}{$\mathrm{Hg}$} & Control (\%) & $47(24.74 \%)$ & $48(25.26 \%)$ & $48(25.26 \%)$ & $47(24.74 \%)$ & \\
\hline & Case (\%) & 15 (10.95\%) & $39(28.47 \%)$ & $34(24.82 \%)$ & 49 (35.77\%) & \\
\hline & AOR $(95 \% \mathrm{Cl})$ & 1 & $1.68(0.72-3.89)$ & $1.69(0.72-3.96)$ & $1.75(0.76-4.03)$ & \\
\hline & $p$ value & & 0.228 & 0.226 & 0.185 & $0.004^{* *}$ \\
\hline \multirow[t]{4}{*}{$\mathrm{Pb}$} & Control (\%) & $47(24.74 \%)$ & $48(25.26 \%)$ & $48(25.26 \%)$ & 47 (24.74\%) & \\
\hline & Case (\%) & $46(33.58 \%)$ & $19(13.87)$ & $17(12.41 \%)$ & $55(40.15 \%)$ & \\
\hline & AOR (95\% Cl) & 1 & $0.37(0.16-0.86)$ & $0.16(0.06-0.44)$ & $0.90(0.46-1.78)$ & \\
\hline & $p$ value & & $0.020^{*}$ & $<0.001^{* *}$ & 0.772 & 0.498 \\
\hline \multirow[t]{4}{*}{$\mathrm{Cr}$} & Control (\%) & $33(24.81 \%)$ & $34(25.56 \%)$ & $33(24.81 \%)$ & $33(24.81 \%)$ & \\
\hline & Case (\%) & $12(15.79 \%)$ & $14(18.42 \%)$ & $11(14.47 \%)$ & 39 (51.32\%) & \\
\hline & AOR $(95 \% \mathrm{Cl})$ & 1 & $1.74(0.51-5.96)$ & $1.65(0.45-6.10)$ & $4.48(1.40-14.31)$ & \\
\hline & $p$ value & & 0.377 & 0.450 & $0.011^{*}$ & $0.002^{* *}$ \\
\hline \multirow[t]{4}{*}{$\mathrm{Cd}$} & Control (\%) & $22(25.29 \%)$ & 22 (25.29\%) & 22 (25.29\%) & 21 (24.14\%) & \\
\hline & Case (\%) & $5(3.65 \%)$ & $16(11.68 \%)$ & $64(46.72 \%)$ & $52(37.96 \%)$ & \\
\hline & AOR $(95 \% \mathrm{Cl})$ & 1 & $3.07(0.69-13.74)$ & $16.87(4.19-67.86)$ & $11.95(2.97-48.04)$ & \\
\hline & $p$ value & & 0.142 & $<0.001^{* *}$ & $<0.001^{* *}$ & $<0.001^{* *}$ \\
\hline
\end{tabular}

${ }^{\mathrm{a}}$ Missing values of $\mathrm{Pb}$ were imputed by $1 / 2 \mathrm{LOD}$ while missing values of $\mathrm{Cr}$ and $\mathrm{Cd}$ were excluded from statistics. Quartiles based on the control group.

binear by linear association. ${ }^{*}$ indicates $\mathrm{p}<0.05,{ }^{* *}$ indicates $\mathrm{p}<0.01$.

CAOR: Adjusted odds ratio. Adjustments made for maternal age, pre-pregnant BMl, gravidity, parity, HBV infection (HBsAg positive), newborn sex. Cl: Confidence Interval.

${ }^{d} p$ value was obtained by binary logistic regression. ${ }^{*}$ indicates $p<0.05,{ }^{* *}$ indicates $p<0.01$.

which could be mainly related to contaminated dietary items [39-41] and dust ingestion [42], as a consequence of rapid industrialization and increasing environmental pollution throughout China. Although no mother reported smoking during pregnancy, the second-hand cigarette smoking is very common in China. This may also be one of the routes for $\mathrm{Cd}$ exposure [43]. The levels of selected metals are higher in our subjects at many instances
(Table 4), which clearly reflected severe environmental pollution in China.

\section{GDM risk from the selected heavy metals}

In current study, we assess that heavy metal exposure may cause considerable risk of GDM prevalence in the investigated cohort, and the As exposure is quite noteworthy. Our results are in agreement with many other

Table 4 Comparison of selected heavy metal levels in meconium (median, $\mathrm{ng} / \mathrm{g}$ ) with the published studies

\begin{tabular}{|c|c|c|c|c|c|c|}
\hline Reference & Area & As & $\mathrm{Hg}$ & $\mathrm{Pb}$ & $\mathrm{Cd}$ & $\mathrm{Cr}$ \\
\hline The present work $(n=327)^{a}$ & Xiamen, China & 42.82 & 30.08 & 137.60 & 7.09 & 34.95 \\
\hline Türker et al., $2013(n=291)$ [37] & West Anatolia, Turkey & - & - & 30.84 & 2.48 & - \\
\hline Vall et al., $2012(n=37)[44]$ & Tenerife Island, Spain & 5.60 & - & - & - & - \\
\hline Gundacker et al., $2010(n=36)$ [38] & Vienna, Austria & - & 4.00 & 15.50 & - & - \\
\hline Li et al., $2008(n=100)$ (mean) [34] & Guiyu, China & - & - & $2.50 \times 10^{3}$ & - & - \\
\hline Unuvar et al., 2007 ( $n=143$ ) (mean) [35] & Istanbul, Turkey & - & $9.45 \times 10^{3}$ & - & - & - \\
\hline Türker et al., 2006 ( $n=117)$ [36] & Kocaeli, Turkey & - & - & $4.65 \times 10^{4}$ & $2.30 \times 10^{3}$ & - \\
\hline Ostrea Jr. et al., $2002(n=426)(p p m)[14]$ & Manila, Philippines & 0.00 & $3.17 \times 10^{-3}$ & 35.77 & 13.37 & - \\
\hline Ramirez et al., $2000(n=36)$ (mean, ppm) [45] & Tagum, Philippines & - & $4.86 \times 10^{-2}$ & - & - & - \\
\hline
\end{tabular}

${ }^{a}$ In the present work, missing values of $\mathrm{Pb}$ were imputed by $1 / 2 \mathrm{LOD}$. Cd values were available from 224 samples and $\mathrm{Cr}$ values were available from 209 samples. 
epidemiologic reports which linked diabetes mellitus to As exposure [46,47]. In some highly As-contaminated regions, the diabetes incidences could be two to five times higher when compared to the non-endemic regions [47]. Moreover, As also caused the maternal GDM risk [48] and previously a research has found a significant relationship between blood arsenic burden and impaired glucose tolerance in 532 US pregnant women [49]. Hence, our observations also support the hypothesis that As exposure may induce maternal GDM risk. Nevertheless, most studies were limited to inhabitants from the highly geogenic arsenic-contaminated areas; while some contradictory findings from less contaminated areas were justified by some other risk factors $[12,50]$. Similar effects have also been observed for $\mathrm{Cr}$ and $\mathrm{Cd}$ exposure in current study but their results are subjected to discrepant and low detection frequencies in the case-control samples, which may lead to some bias assessments. $\mathrm{Cd}$ exposure has been linked to diabetes risk in general population but the effects have not been confirmed yet [51,52]. Likewise, the role of trivalent $\mathrm{Cr}$ in controlling blood glucose is still controversial [53]. Thus, more detailed epidemiological studies are required to explore the effects of these metals. On the other hand, $\mathrm{Pb}$ and $\mathrm{Hg}$ have also been suggested to induce diabetes $[54,55]$ and insulin resistance [56], respectively. However, the conclusions majorly came from special high-exposed populations, e.g. occupational workers [55] and Minamata disease patients [56].

\section{Strengths and limitations of this study}

Our study provides the evidence that meconium is a novel non-invasive matrix for the surveillance of heavy metals during pregnancy, which can be mutually used to assess both prenatal children and gestational mothers' exposure. In addition, meconium is formed in fetus 12 weeks earlier than maternal GDM diagnosis, which proves itself as an efficient tool to reflect the chronic exposure from the early pregnancy to the delivery. Our pilot work also showed the authentication of meconium as an effective monitoring tool in the large cohort study.

The quality of study design was ensured by following the universal GDM diagnostic criteria [19] with full consideration of confounders [47]. All potential cofounders, including gestational complications and clinical characteristics were carefully assessed between the GDM and non-GDM mothers (Additional file 1: Tables S2 and S3); and finally 6 risk factors were fully adjusted in GDM risk assessment. Our criteria to recruit controls were very stringent and we included only 190 apparently healthy mothers from 1193 non-GDM mothers. To identify potential selection bias in study group, clinical characteristics were compared between 327 selected mothers in nested case-control group and other 1032 non-selected mothers (Additional file 1: Table S8). Among all the potential risk factors, only parity and HBV infection were significantly different $(p<0.05)$ between selected and non-selected mothers but we believe that adjustments made for them have addressed this problem. Therefore, this nested case-control study would be fine-tuned to generally reflect the whole population's condition.

Although GDM is not a rare disease, but the nested case-control sample size is still not large enough. Some missing clinical records led to 36 unavailable values of maternal age or pre-pregnant BMI in case group, which is an inherent limitation due to the nature of retrospective study. In addition, the low and discrepant detection of $\mathrm{Cr}$ and $\mathrm{Cd}$ may lead to bias and questionable results. Moreover, the species specific effects of $\mathrm{Cr}$ (i.e., highly toxic hexavalent but nutrient trivalent $\mathrm{Cr}$ ) and $\mathrm{As}$ on the GDM development may reveal different effects. Therefore, the species specific measurements for these metals are expected in the further studies.

\section{Conclusions}

Our pilot study showed the linkages of the selected heavy metal to maternal GDM risk, which implies that these heavy metals should be paid more attention. Although our finding supports the hypothesis that some metals (noticeably As) pose additional risk to GDM prevalence, more detailed toxicological information is required to support the observation. Meanwhile, our study provides the evidence that meconium is a useful matrix to assess both prenatal children and gestational mothers' exposure to selected heavy metals during pregnancy.

\section{Additional file}

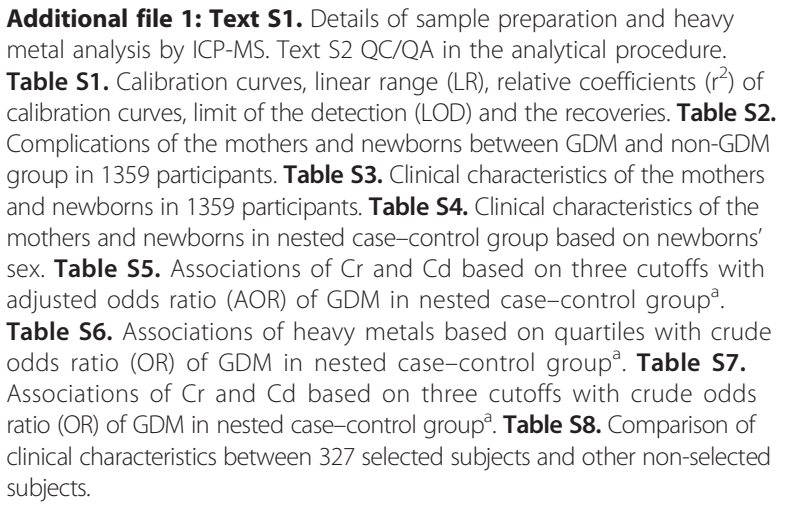

\section{Abbreviations}

GDM: Gestational diabetes mellitus; As: Arsenic; Hg: Mercury; Pb: Lead Cd: Cadmium; Cr: Chromium; ICP-MS: Inductively coupled plasma mass spectrometry; LOD: Limit of detection; BMI: Body mass index; T2DM: Type 2 diabetes; IGT: Impaired glucose tolerance; OGTT: Oral glucose tolerance test; WHO: World Health Organization; HBV: Hepatitis B virus; Cl: Confidence interval; OR: Odds ratio; AOR: Adjusted odds ratio. 


\section{Competing interests}

The authors declare that they have no competing interests.

\section{Authors' contributions}

SP and LL contribute equally; SP and LL prepared the samples and SP carried out the heavy metals determination, performed the statistical analysis and drafted the manuscript. XZ participated in the subject recruitment and interviews and sample collection. JH helped to improve the statistical analysis. HS conceived the study, and participated in the design and coordination of the study, and helped to draft the manuscript. KWS participated in the study design. LL, SAMASE, JZ, QH and MT helped to draft the manuscript. All authors read and approved the final manuscript.

\section{Acknowledgements}

We thank Ms Tongwei Xia, and Ms Yue Yang to participate in the sampling procedure, we also thank all the mothers who contributed their samples, the midwife and nurses from Xiamen Maternity and Child Health Care Hospital to offer their kind help in this study. The work was supported by CAS 100 Talents Program of Human Exposure to Environmental Pollutant and Health Effect, the National Nature Science Foundation of China (NSFC 21177123; 21407144), CAS/SAFEA International Partnership Program for Creative Research Teams (KZCX2-YW-T08).

\section{Author details}

${ }^{1}$ Key Laboratory of Urban Environment and Health, Institute of Urban Environment, Chinese Academy of Sciences, Xiamen 361021, PR China. ${ }^{2}$ Xiamen Maternity and Child Health Care Hospital, Xiamen 361003, PR China. ${ }^{3}$ Institutfür Epidemiologie I, Helmholtz Zentrum München - German Research Center for Environmental Health (GmbH), Ingolstädter Landstr. 1, 85764 Neuherberg, Germany. ${ }^{4}$ Molecular EXposomics (MEX), Helmholtz Zentrum München - German Research Center for Environmental Health $(\mathrm{GmbH})$, Ingolstädter Landstr.1, 85764 Neuherberg, Germany. ${ }^{5}$ Department für Biowissenschaftliche Grundlagen, Technische Universität München, Weihenstephaner Steig 23, 85350 Freising, Germany. ${ }^{6}$ Public Health and Environment Division, Department of Biosciences, COMSATS Institute of Information and Technology, Islamabad, Pakistan.

\section{Received: 13 August 2014 Accepted: 5 February 2015}

\section{Published online: 28 February 2015}

\section{References}

1. Meetoo D, McGovern P, Safadi R. An epidemiological overview of diabetes across the world. Br J Nurs. 2007;16:1002-7.

2. Ma RC, Chan JC. Pregnancy and diabetes scenario around the world: China. Int J Gynaecol Obstet. 2009;104:S42-5.

3. Hyer S, Shehata H. Gestational diabetes mellitus. Curr Obstet Gyn. 2005;15:368-74.

4. Gilmartin A, Ural S, Repke J. Gestational diabetes mellitus. Rev Obstet Gynecol. 2007;1:129-34.

5. Coughlan M, Vervaart P, Permezel M, Georgiou H, Rice G. Altered placental oxidative stress status in gestational diabetes mellitus. Placenta. 2004;25:78-84.

6. Zimmet P, Alberti K, Shaw J. Global and societal implications of the diabetes epidemic. Nature. 2001;414:782-7.

7. Hectors T, Vanparys C, van der Ven K, Martens G, Jorens P, Van Gaal L, et al. Environmental pollutants and type 2 diabetes: a review of mechanisms that can disrupt beta cell function. Diabetologia. 2011;54:1273-90.

8. Carpenter DO. Environmental contaminants as risk factors for developing diabetes. Rev Environ Health. 2008;23:59-74.

9. Alonso-Magdalena P, Morimoto S, Ripoll C, Fuentes E, Nadal A. The estrogenic effect of bisphenol A disrupts pancreatic $\beta$-cell function in vivo and induces insulin resistance. Environ Health Perspect. 2006;114:106-12.

10. Chen YW, Yang CY, Huang CF, Hung DZ, Leung YM, Liu SH. Heavy metals, islet function and diabetes development. Islets. 2009;1:169-76.

11. Edwards JR, Prozialeck WC. Cadmium, diabetes and chronic kidney disease. Toxicol Appl Pharmacol. 2009;238:289-93.

12. Huang CF, Chen YW, Yang CY, Tsai KS, Yang RS, Liu SH. Arsenic and diabetes: current perspectives. Kaohsiung J Med Sci. 2011;27:402-10.

13. Casals-Casas C, Desvergne B. Endocrine disruptors: from endocrine to metabolic disruption. Annu Rev Physiol. 2011;73:135-62.
14. OstreaJr EM, Morales V, Ngoumgna E, Prescilla R, Tan E, Hernandez E, et al. Prevalence of fetal exposure to environmental toxins as determined by meconium analysis. Neurotoxicology. 2002;23:329-39.

15. Barr DB, Wang RY, Needham LL. Biologic monitoring of exposure to environmental chemicals throughout the life stages: requirements and issues for consideration for the National Children's Study. Environ Health Perspect. 2005;113:1083-91.

16. Posecion NC, Ostrea EM, Bielawski DM. Quantitative determination of paraquat in meconium by sodium borohydride-nickel chloride chemical reduction and gas chromatography/mass spectrometry (GC/MS). J Chromatogr, B. 2008;862:93-9.

17. Zhao G, Xu Y, Li W, Han G, Ling B. Prenatal exposures to persistent organic pollutants as measured in cord blood and meconium from three localities of Zhejiang, China. Sci Total Environ. 2007;377:179-91.

18. Kazi TG, Afridi HI, Kazi N, Jamali MK, Arain MB, Jalbani N, et al. Copper, chromium, manganese, iron, nickel, and zinc levels in biological samples of diabetes mellitus patients. Biol Trace Elem Res. 2008;122:1-18.

19. Alberti K, Zimmet P. Definition, diagnosis and classification of diabetes mellitus and its complications. Part 1: diagnosis and classification of diabetes mellitus. Provisional report of a WHO consultation. Diabet Med. 1998;15:539-53.

20. Desai M, Kubo J, Esserman D, Terry MB. The handling of missing data in molecular epidemiology studies. Cancer Epidemiol Biomarkers Prev. 2011;20:1571-9.

21. Hopke PK, Liu C, Rubin DB. Multiple imputation for multivariate data with missing and below-threshold measurements: time-series concentrations of pollutants in the arctic. Biometrics. 2001;57:22-33.

22. Bornehag CG, Sundell J, Weschler CJ, Sigsgaard T, Lundgren B, Hasselgren M, et al. The association between asthma and allergic symptoms in children and phthalates in house dust: a nested case-control study. Environ Health Perspect. 2004;112:1393-7.

23. Salem Yaniv S, Levy A, Wiznitzer A, Holcberg G, Mazor M, Sheiner E. A significant linear association exists between advanced maternal age and adverse perinatal outcome. Arch Gynecol Obstet. 2011;283:755-9.

24. Gilbert JS, Nijland MJ. Sex differences in the developmental origins of hypertension and cardiorenal disease. Am J Physiol Regul Integr Comp Physiol. 2008;295:R1941-52.

25. Tse KY, Ho LF, Lao T. The impact of maternal HBsAg carrier status on pregnancy outcomes: a case-control study. J Hepatol. 2005:43:771-5.

26. Lao TT, Chan BC, Leung WC, Ho LF, Tse KY. Maternal hepatitis B infection and gestational diabetes mellitus. J Hepatol. 2007:47:46-50.

27. American Diabetes Association. Gestational diabetes mellitus. Dabetes Care. 2004;27:88-S90.

28. Yang H, Wei Y, Gao X, Xu X, Fan L, He J, et al. Risk factors for gestational diabetes mellitus in Chinese women-a prospective study of 16286 pregnant women in China. Diabet Med. 2009;26:1099-104.

29. Cheung NW, Wasmer G, Al-Ali J. Risk factors for gestational diabetes among Asian women. Diabetes Care. 2001;24:955-6.

30. Hyman MA. Environmental toxins, obesity, and diabetes: an emerging risk factor. Altern Ther Health Med. 2010;16:56-8.

31. Llanos MN, Ronco AM. Fetal growth restriction is related to placental levels of cadmium, lead and arsenic but not with antioxidant activities. Reprod Toxicol. 2009;27:88-92.

32. Hubermont G, Buchet J, Roels H, Lauwerys R. Placental transfer of lead, mercury and cadmium in women living in a rural area. Int Arch Occup Environ Health. 1978;41:117-24.

33. Tsuchiya H, Mitani K, Kodama K, Nakata T. Placental transfer of heavy metals in normal pregnant Japanese women. Arch Environ Health. 1984;39:11-7.

34. Li Y, Xu X, Wu K, Chen G, Liu J, Chen S, et al. Monitoring of lead load and its effect on neonatal behavioral neurological assessment scores in Guiyu, an electronic waste recycling town in China. J Environ Monit. 2008; 10:1233-8.

35. Unuvar E, Ahmadov H, Kizıler AR, Aydemir B, Toprak S, Ulker V, et al. Mercury levels in cord blood and meconium of healthy newborns and venous blood of their mothers: clinical, prospective cohort study. Sci Total Environ. 2007;374:60-70.

36. Türker G, Ergen K, Karakoç Y, Arısoy A, Barutcu U. Concentrations of toxic metals and trace elements in the meconium of newborns from an industrial city. Neonatology. 2006;89:244-50.

37. Türker G, Özsoy G, Özdemir S, Barutçu B, Gökalp AS. Effect of heavy metals in the meconium on preterm mortality: preliminary study. Pediatr Int. 2013;55:30-4. 
38. Gundacker C, Fröhlich S, Graf-Rohrmeister K, Eibenberger B, Jessenig V, Gicic D, et al. Perinatal lead and mercury exposure in Austria. Sci Total Environ. 2010:408:5744-9.

39. Xu W, Shen H. Arsenic exposure induced male reproductive effects: a brief review. Chin Sci Bull. 2014;59:238-44.

40. Zhang J, Liu F, Chen R, Feng T, Dong S, Shen H. Levels of polychlorinated biphenyls and organochlorine pesticides in edible shellfish from Xiamen (China) and estimation of human dietary intake. Food Chem Toxicol. 2012;50:4285-91.

41. Liu F, Ni HG, Chen F, Luo ZX, Shen H, Liu L, et al. Metal accumulation in the tissues of grass carps (Ctenopharyngodonidellus) from fresh water around a copper mine in Southeast China. Environ Monit Assess. 2012;184:4289-99.

42. Huang Q, Zhang J, Peng S, Tian M, Chen J, Shen H. Effects of water soluble PM2. 5 extracts exposure on human lung epithelial cells (A549): a proteomic study. J Appl Toxicol. 2014;34:675-87.

43. Järup L. Hazards of heavy metal contamination. BritMed Bull. 2003;68:167-82

44. Vall O, Gómez-Culebras M, Garcia-Algar O, Joya X, Velez D, Rodríguez Carrasco E, et al. Assessment of prenatal exposure to arsenic in Tenerife Island. PLoS One. 2012;7:e50463.

45. Ramirez GB, Cruz MCV, Pagulayan O, Ostrea E, Dalisay C. The Tagum study I: analysis and clinical correlates of mercury in maternal and cord blood, breast milk, meconium, and infants' hair. Pediatrics. 2000;106:774-81.

46. Maull EA, Ahsan H, Edwards J, Longnecker MP, Navas-Acien A, Pi J, et al. Evaluation of the association between arsenic and diabetes: a national toxicology program workshop review. Environ Health Perspect. 2012;120:1658-70.

47. Tseng CH, Tseng CP, Chiou HY, Hsueh YM, Chong CK, Chen CJ. Epidemiologic evidence of diabetogenic effect of arsenic. Toxicol Lett. 2002;133:69-76.

48. Navas-Acien A, Silbergeld EK, Streeter RA, Clark JM, Burke TA, Guallar E. Arsenic exposure and type 2 diabetes: a systematic review of the experimental and epidemiologic evidence. Environ Health Perspect. 2006;114:641-8.

49. Barrett JR. Mother Load: arsenic may contribute to gestational diabetes. Environ Health Perspect. 2009;117:A310.

50. Tseng CH, Tai TY, Chong CK, Tseng CP, Lai MS, Lin BJ, et al. Long-term arsenic exposure and incidence of non-insulin-dependent diabetes mellitus: a cohort study in arseniasis-hyperendemic villages in Taiwan. Environ Health Perspect. 2000;108:847-51.

51. Afridi HI, Kazi TG, Kazi N, Jamali MK, Arain MB, Jalbani N, et al. Evaluation of status of toxic metals in biological samples of diabetes mellitus patients. Diabetes Res Clin Pract. 2008;80:280-8.

52. Schwartz GG, Il'yasova D, Ivanova A. Urinary cadmium, impaired fasting glucose, and diabetes in the NHANES III. Diabetes Care. 2003;26:468-70.

53. Cefalu WT, Hu FB. Role of chromium in human health and in diabetes. Diabetes Care. 2004;27:2741-51.

54. Akinloye O, Ogunleye K, Oguntibeju O. Cadmium, lead, arsenic and selenium levels in patients with type 2 diabetes mellitus. Afr J Biotechnol. 2013:9:5189-95.

55. Bener A, Obineche E, Gillett M, Pasha M, Bishawi B. Association between blood levels of lead, blood pressure and risk of diabetes and heart disease in workers. Int Arch Occup Environ Health. 2001;74:375-8.

56. Chang JW, Chen HL, Su HJ, Liao PC, Guo HR, Lee CC. Simultaneous exposure of non-diabetics to high levels of dioxins and mercury increases their risk of insulin resistance. J Hazard Mater. 2011;185:749-55.

\section{Submit your next manuscript to BioMed Central and take full advantage of:}

- Convenient online submission

- Thorough peer review

- No space constraints or color figure charges

- Immediate publication on acceptance

- Inclusion in PubMed, CAS, Scopus and Google Scholar

- Research which is freely available for redistribution 